\title{
A CONCEPTUAL DESIGN OF AN INTERNAL INJECTION ABSORBER OF 8 GEV H- INJECTION INTO THE FERMILAB MAIN INJECTOR*
}

\author{
D.E. Johnson" ${ }^{\#}$ A. Chen, I. Rakhno, FNAL, Batavia, IL, USA
}

\begin{abstract}
An $8 \mathrm{GeV}$ superconducting linear accelerator (SCL) has been proposed as a single stage $\mathrm{H}^{-}$injector into the Main Injector (MI) synchrotron[1]. This would be the highest energy $\mathrm{H}$ - multi-turn injection system in the world. An injection absorber is required to absorb a few percent 0 the incoming beam on a regular pulse by pulse basis. The requirements and conceptual design of an internal absorber, capable of steady state $6.5 \mathrm{~kW}$ is discussed.
\end{abstract}

\section{MOTIVATION}

The conceptual design of a compact internal injection absorber was motivated by several factors. The first was to reduce the time and cost of constructing an external absorber and absorber room. This would have been a significant civil construction project and would have disrupted the MI tunnel and accelerator in a complicated area. The second motivation was the reduction in complexity of the transport line between the stripping foil and the absorber.

\section{BEAM PARAMETERS}

To provide 2MW of proton power at $120 \mathrm{GeV} / \mathrm{c}$ on a neutrino target, the linac delivers $1.54 \mathrm{E} 14$ protons every $1.5 \mathrm{sec}$. The injection will initially take place over $3 \mathrm{msec}$. (270 turns) and ultimately, with added linac RF power (X3), over 1 msec. (100 turns). This keeps the injected power constant at $132 \mathrm{~kW}$. The injection process will use transverse painting [2] and routinely send approximately $5 \%$ ( $2 \%$ foil miss and $3 \% \mathrm{H} 0$ ) to the absorber. This corresponds to 5.13E12 protons/sec into the absorber or $1.02 \mathrm{E} 20$ protons on the absorber per Fermilab beam year which consists of 5500 hours of beam-on time/year. This corresponds to $6.5 \mathrm{~kW}$ beam power on the absorber.

\section{ABSORBER GEOMETRY}

\section{Core box design}

The core box is patterned after the MI design [3]. It is comprised six of 6 inch diameter by 6 inch long graphite cylinders inside an aluminum water jacket with three inch thick walls with cooling channels for water cooling. The core box is recessed ten inches from the end of the tungsten which produces a collar or "end-plug" with a 3 inch hole at the entrance to the absorber for the beam pipe.

*Operated by Fermi Research Alliance, LLC under contract No. DEAC02-07CH11359 with the United States Department of Energy \#dej@fnal.gov

\section{Shielding design}

A MARS [4] model was constructed of the absorber and surrounding tunnel geometry. Figure 1 shows the plan view of the absorber and tunnel geometry. The graphite core (blue) and aluminum jacket (red) make up the core box. The first layer after the core box consists of a tapered thickness of tungsten (yellow) with the thickest part being 6 inches, located at the transverse shower maximum. The tungsten is surrounded by 20 inches of iron to contain secondary shower. The iron is followed by 8 inches of concrete on all sides and ends. The external dimension of the absorber is 88 inches wide, 120 inches long, and 67 inches tall. The centerline of the absorber is 27 inches above the MI tunnel floor. Also shown in figure 1 is the only magnet (dipole) in the injection absorber beam line and the 3 inch round beam pipe into the face of the absorber. The face of the injection absorber is located about 7 meters downstream of the stripping foil.

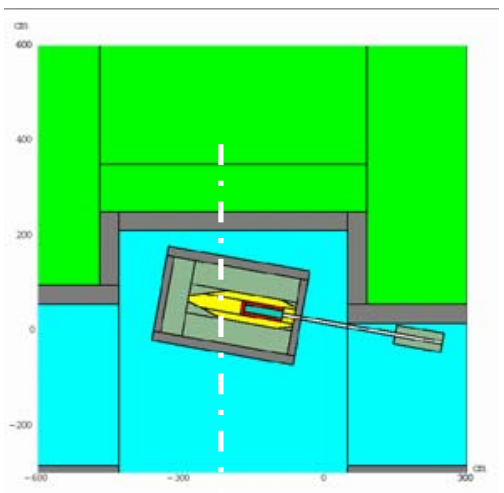

Figure 1: Plan view of the MARS absorber and tunnel geometry.

The model includes a walkway between the Service Building an tunnel entrance door at surface elevation. The shielding above the tunnel outside ceiling and walkway floor consists of 22 feet of soil and $1 \frac{1 / 2}{2}$ feet of concrete. The longitudinal location of the walkway is just downstream of the shower max. This is depicted in the cross section in Figure 2. The area enclosed by the white dashed line represents the plot limits for the prompt dose calculations (see Figure 5).

\section{SURFACE WATER ACTIVATION}

As a result of numerous studies on surface water activation at Fermilab, it has been determined that, in order to comply with the radiclogical limits [5], the maximum star density in the un-controlled soil should not exceed $3.5 \times 10^{4} \mathrm{~cm}^{-3} \mathrm{~s}^{-1}$. One can see from Figs. 3 and 4 that the maximum star density of $2.7 \times 10^{4} \mathrm{~cm}^{-3} \mathrm{~s}^{-1}$ is observed under the tunnel concrete floor. A white circle 


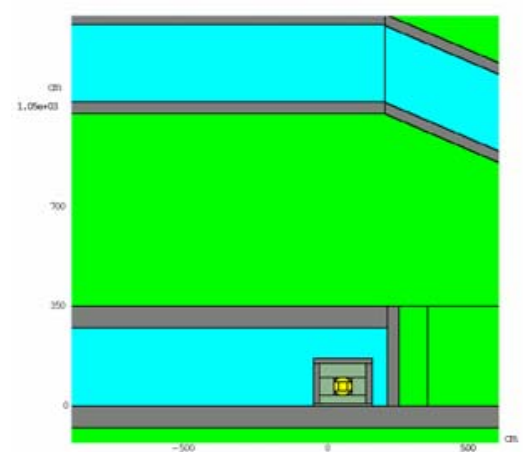

Figure 2: Model cross sections at face and core box face.

in figure 3 indicates the approximate location of a sump line designed to collect surface water to be pumped into the cooling ponds. The maximum star density at this location is a factor 10 smaller than the area below the tunnel.

Due to the small measured seepage rated around the MI tunnel, contamination of ground water is not an issue.[6]

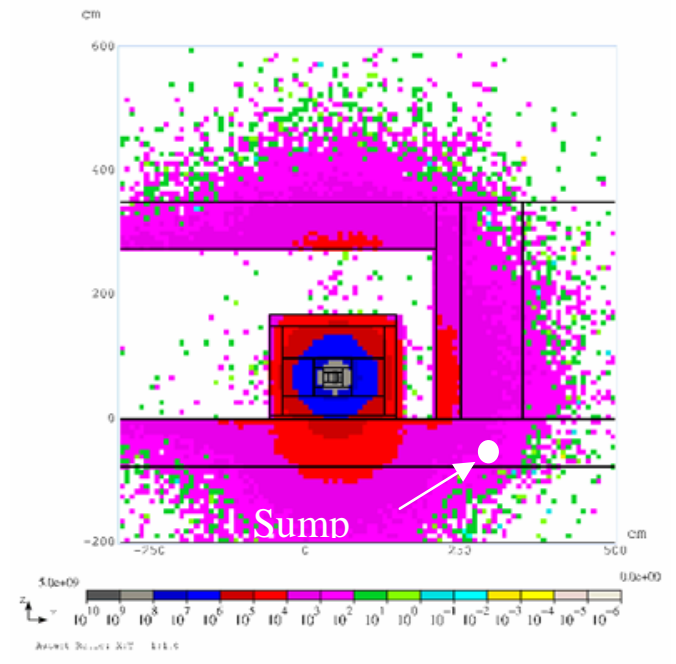

Figure 3: Elevation view of star density at the shower maximum. The units are stars $/ \mathrm{cm}^{3} / \mathrm{sec}$.

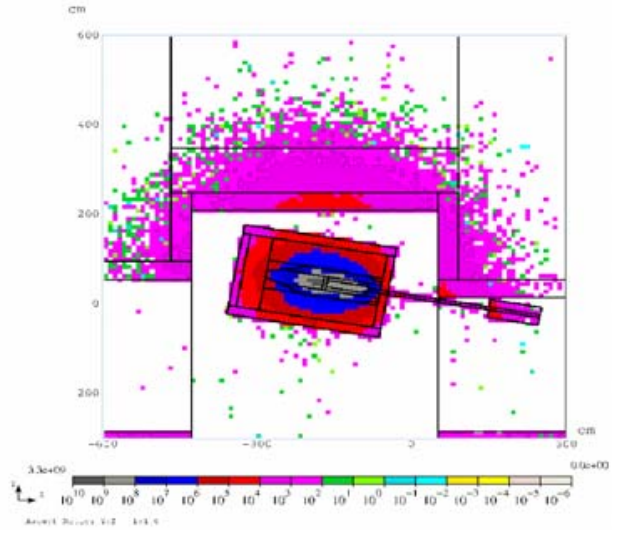

Figure 4: Plan view of star density in the unprotected soil. The units are stars $/ \mathrm{cm}^{3} / \mathrm{sec}$.

\section{PROMPT RADIATION}

\section{Prompt dose in the walkway}

The distribution of prompt dose was calculated around the absorber as shown in Figure 5. In order to estimate the dose in the walkway, an attenuation factor, corresponding to 23.5 feet of soil, is applied to the dose observed on the top of the concrete ceiling at the elevation of $\mathrm{X}=350 \mathrm{~cm}$ [7]. For a power of $6.5 \mathrm{~kW}$ the predicted prompt dose in the walkway is $0.002 \mathrm{mrem} / \mathrm{hr}$, well under the limit for unlimited occupancy. Scaling this by a factor of 15 to estimate the prompt dosage at $100 \mathrm{~kW}$ of power, yields only $0.03 \mathrm{mrem} / \mathrm{hr}$ which would require no additional posting different from the Service Building.

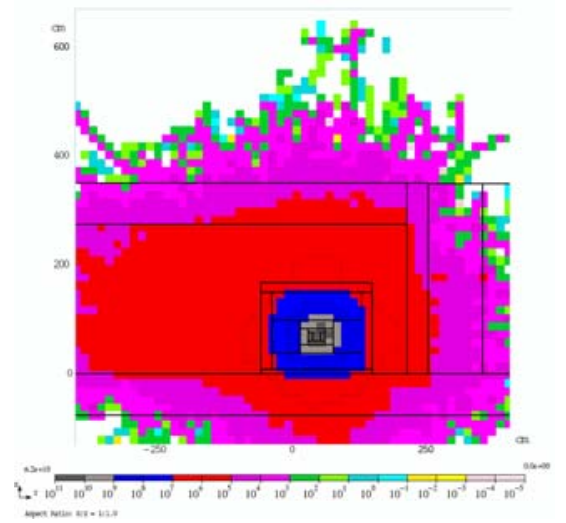

Figure 5 Prompt radiation in mrem/hr with $6.5 \mathrm{~kW}$ on the absorber.

\section{RESIDUAL ACTIVATION}

The residual activation of the absorber and surrounding tunnel has been calculated. The simulations assume the standard 30 day irradiation and 1 day cool down with the nominal beam power of $6.5 \mathrm{~kW}$. The results are given in terms of $\mathrm{mSv} / \mathrm{hr}$ with $1 \mathrm{mSv} / \mathrm{hr}=100 \mathrm{mrem} / \mathrm{hr}$. The results are shown in Figure 6.
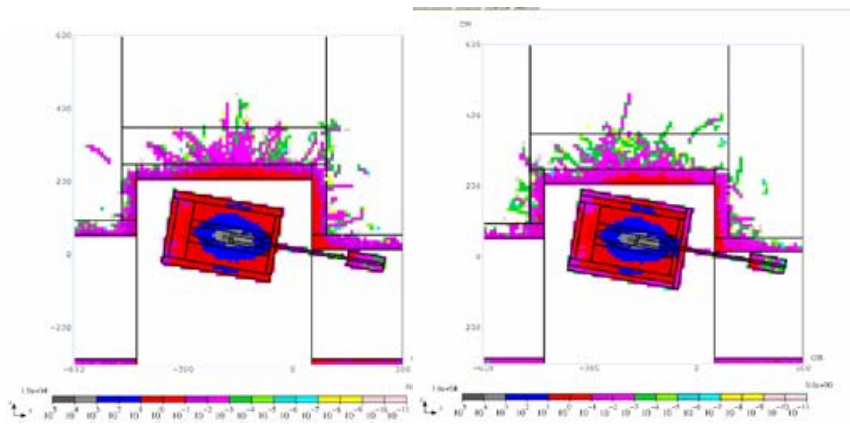

Figure 6: Residual activity after a 30 day irradiation and 1 day cool down for nominal beam power with (right) and without (left) external marble layer.

Figure 6 shows the residual activation levels of the initial model (without marble) and with the addition of a 6 
inch marbel layer. The hottest spot on the exterior without the marble is approximately $900 \mathrm{mrem} / \mathrm{hr}$ on either side. The front face level is $500 \mathrm{mrem} / \mathrm{hr}$ and the rear end is less than $100 \mathrm{mrem} / \mathrm{hr}$. Adding a 6 inch external layer of marble reduced these levels to $40 \mathrm{mrem} / \mathrm{hr}$ on the sides and $30 \mathrm{mrem} / \mathrm{hr}$ on the front face. The absorbed dose on the face of the upstream dipole is less than $0.1 \mathrm{MGy} / \mathrm{yr}$, which is well below the level of concern to reach an integrated does of 4MGy for coil insulation damage. The highest residual dose on the face of the dipole is well below $100 \mathrm{mrem} / \mathrm{hr}$.

\section{ABSORBER CORE BOX HEATING}

A preliminary ANSYS simulation was performed to investigate the heating of the absorber. Shockwave analysis was not performed due to the time structure of the beam being on the order of milliseconds rather than microseconds.

Beam energy is deposited in the absorber with azimuthally symmetry. A 2D energy distribution result from MARS is input as heat source. Only a quarter of the absorber was simulated in ANSYS since symmetry. An equivalent water cooling of $1000 \mathrm{~W} / \mathrm{m}^{2} \mathrm{~K}(10 \%$ of normal, because a real cooling channel has smaller surface) was applied on the outer surfaces of Aluminum core box, and $5 \mathrm{~W} / \mathrm{m}^{2} \mathrm{~K}$ air cooling on the outer surfaces of Tungsten. The room temperatures of water and air are set to $35 \mathrm{C}^{\circ}$. The thermal resistance at the interfaces of graphiteAluminum and Aluminum-Tungsten was not simulated for simplicity.

\section{Nominal Operation}

ANSYS static results for both normal operation and failure of water cooling are presented. For normal operation, the maximum temperature of $63 \mathrm{C}^{\circ}$ occurs on the axial upstream of Tungsten as seen in Figure 7.

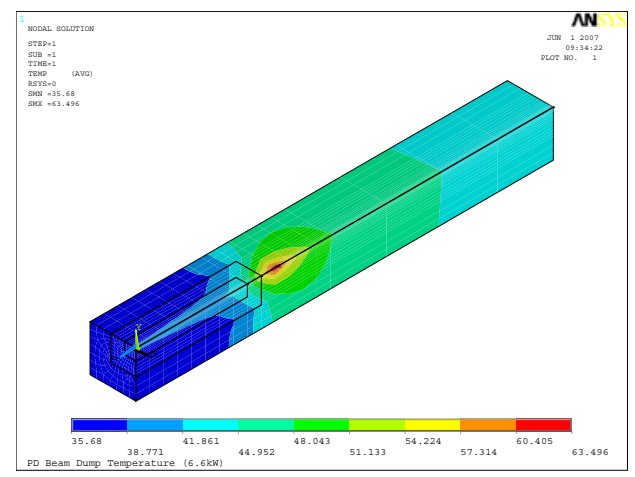

Figure 7: ANSYS heating results for $6.5 \mathrm{~kW}$ beam power with water cooling during normal operation.

\section{Cooling failure}

One of modes of failure to be considered for a water cooled injection absorber is the failure of the cooling water system. In the event of the lack of cooling water the integrity injection absorber must not be compromised. The steady state temperature in the case of no cooling was found to be $287 \mathrm{C}^{\circ}$ in the upstream end of the tungsten absorber, well below the melting temperature of $3700 \mathrm{~K}^{\circ}$ as shown in Figure 8.

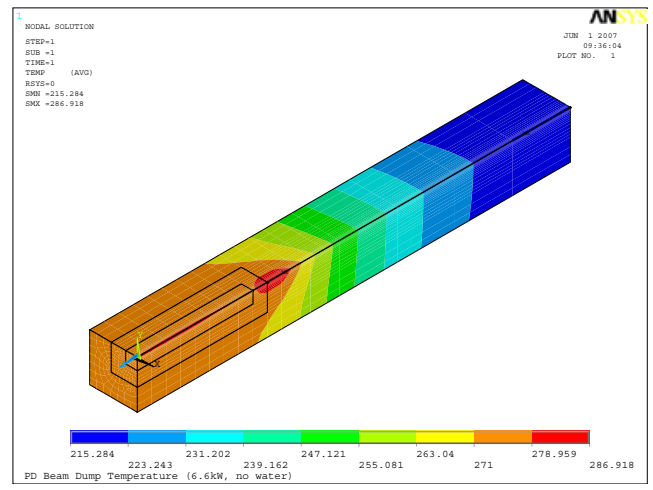

Figure 8. Steady state heating of injection absorber for nominal $6.5 \mathrm{~kW}$ beam power and no water cooling.

\section{Worst case Accident}

The absorber protection system will protect the absorber from damage and personnel from accidental prompt dose. The absorber core box will be temperature protected via imbedded thermocouples. In addition the losses on the absorber and beam intensity on each pulse will be measured and monitored. These signals will be connected to the existing beam permit system which will inhibit the beam at the linac ion source. In the case of full injection power of $131 \mathrm{~kW}$ is directed to the absorber the steady state temperature rises to $623 \mathrm{C}^{\circ}$, still well below the melting point of tungsten.

\section{SUMMARY}

We have presented a conceptual design for an internal absorber with a yearly design intensity of $1.02 \mathrm{E} 20$ protons. The design meets all requirements for surface and ground water contamination and ALARA personnel protection.

\section{REFERENCES}

[1] G. W. Foster, J. A. MacLachlan, ”A Multi-mission 8 $\mathrm{GeV}$ Injector Linac as a Fermilab Booster Replacement”, Proceedings of LINAC2002, Gyeongju, Korea, p.826.

[2] D. E. Johnson, et. al., "An $8 \mathrm{GeV} \mathrm{H}$ Multi-turn Injection System for the Fermilab Main Injector”, TUPAS020, this conference.

[3] M. Reichanadter, et. al., "A High Intensity Beam Absorber Corebox fot the Fermilab Main Injector”, 1997 Particle Accelerator Conference, p. 243.

[4] N.V. Mokhov, S.I. Striganov, "MARS15 Overview”, Fermilab-Conf-07/008-AD (2007).

[5] "Fermilab Radiological Control Manual”, http://wwwesh.fnal.gov/FRCM/

[6] K.Vaziri, et. al., "Tritium Concentration Reduction Factors for MI30, MI40, MI52, an MI62 locations”, Enviromental Physics Note \#18, March 2000.

[7] “The Proton Driver Design Study”, Fermilab-TM2136, Chapter 10.4.4 (2000). 
